\section{Estudio seroepidemiológico y entomológico sobre la enfermedad de Chagas en un área infestada por Triatoma maculata (Erichson 1848) en el centro-occidente de Venezuela}

\author{
An entomological and seroepidemiological study \\ of Chagas' disease in an area in central-western \\ Venezuela infested with Triatoma maculata \\ (Erichson 1848)
}

\author{
María Elena Rojas 1 \\ Philricar Várquez ${ }^{1}$ \\ María Fernanda Villarreal 1 \\ Carlos Velandia 1 \\ Luis Vergara 1 \\ Yeinmy Heliannie Morán-Borges ${ }^{1}$ \\ Judith Ontiveros ${ }^{1}$ \\ María Yelitza Calderón ${ }^{2}$ \\ Miguel Ángel Chiurillo-Siervo ${ }^{1}$ \\ Claudina del Carmen Rodríguez-Bonfante 1 \\ Elis Aldana 2 \\ Juan Luis Concepción 2 \\ Rafael Armando Bonfante-Cabarcas 1
}

\title{
Introducción
}

${ }_{1}^{1}$ Decanato de Medicina, Universidad CentroOccidental "Lisandro Alvarado", Barquisimeto, Venezuela.

2 Facultad de Ciencias, Universidad de Los Andes, Mérida, Venezuela.

Correspondencia R. A. Bonfante-Cabarcas Unidad de Bioquímica Decanato de Medicina, Universidad CentroOccidental "Lisandro Alvarado".

Av. Libertador con Andrés Bello, Barquisimeto, Estado Lara, Venezuela, 3001. rcabarca@ucla.edu.ve

\begin{abstract}
This article presents a study on seroepidemiological, entomologic, and risk factors for domiciliary infestation in a circumscribed area infested with Triatoma maculata in Parroquia Xaguas, Urdaneta Municipality, Lara State, Venezuela. One hundred and forty households, 509 persons, and 110 dogs were sampled. Serum anti-Trypanosoma cruzi antibodies were determined by means of ELISA and MABA techniques using recombinant antigens. Tr. cruzi infection in the triatomines was determined by direct microscopy and PCR. According to the results, $1.57 \%$ of humans and $6.36 \%$ of dogs were positive for serum anti-Tr. cruzi antibodies. Triatomine species were: $97.98 \%$ T. maculata, $1.65 \%$ Eratyrus mucronatus, and 0.37\% Panstrongylus geniculatus. Vector indices were: $0.36 \%$ vector infection, $16.4 \%$ household infestation, $39.1 \%$ household colonization, $8.6 \%$ household co-infestation, and $100 \%$ vector dispersion. Domiciliary and peridomiciliary infestation was associated with the presence of chickens and disorderly goat corrals, chicken coops, and domiciliary distribution. The results strongly suggest that $\mathrm{T}$. maculata is the predominant $\mathrm{Tr}$. cruzi vector in the area and that due to its capacity to infest and colonize human dwellings, it could be involved in Chagas' disease transmission.
\end{abstract}

Triatoma maculata; Trypanosoma cruzi; Chagas' Disease; Risk Factors
La enfermedad de Chagas o tripanosomiasis americana es una hemoparasitosis causada por el Trypanosoma cruzi, transmitido naturalmente a los mamíferos y al hombre por insectos hematófagos de la subfamilia Triatominae. Es endémica en 21 países del continente americano, donde se estima que existen de 18 a 20 millones de personas infectadas y 100 millones en riesgo de infección 1 .

En Venezuela, en los últimos cuarenta años se ha observado un descenso progresivo de los índices de prevalencia, desde un $44,5 \%$ en la década de los años 50 a 602 , pasando por un 9,2\% en los años 903 hasta un 8,3\% en el año 20004 Estos resultados han sido producto de la puesta en práctica de acciones que incluyen: sustitución de viviendas, control de vectores, cribado de sangre y programas de prevención en áreas vulnerables 3 .

Sin embargo, estudios recientes - realizados en los estados centro-occidentales y nor-orientales de Venezuela por científicos independientes - han revelado prevalencias entre el 11,2\% y $16,3 \%$, con una distribución por estados de: $12,6 \%$ al $30,8 \%$ en Cojedes; $22,8 \%$ al $25,7 \%$ en Barinas; $11 \%$ al $23,8 \%$ en Trujillo; $19,4 \%$ en Portuguesa; $7,3 \%$ al $14 \%$ en Mérida; 7,8\% en Yaracuy; 1,5\% al 2,9\% en Falcón, detectándose un 2,08\% de casos agudos entre los seropositivos. Asimismo, al analizar pacientes referidos a centros de 
salud con diagnóstico presuntivo de enfermedad de Chagas, se logró observar frecuencias entre $44,6 \%$ y $64,8 \%$ de casos agudos entre los seropositivos 5,6,7. De la misma manera, este equipo de trabajo realizó recientemente un estudio en el municipio Andrés Eloy Blanco, Estado Lara, encontrando una prevalencia de anticuerpos antiTr. cruzi del 6,9\%, observándose que 8,33\% de los seropositivos eran niños menores de 10 años 8 . Estos resultados plantean la existencia de una transmisión activa de la enfermedad de Chagas de proporciones preocupantes en Venezuela.

La demostración de transmisión activa requiere la comprobación de casos infectados recientemente, como sería la demostración de casos agudos y/o de seropositividad en niños lactantes, sin embargo, en la mayoría de los individuos infectados la etapa aguda es inaparente y con el avance en el bienestar sociocultural de las sociedades modernas, los niños están cada vez menos expuestos al contacto con los triatominos en las áreas endémicas. Por lo tanto, los estudios seroepidemiológios en humanos tienen significado limitado para demostrar la presencia de transmisión activa de la enfermedad de Chagas en un área determinada.

En el medio rural el canino es un animal que está muy expuesto a los triatominos por su lugar de descanso y porque es un animal que no es estático, presenta un movimiento constante entre el domicilio y peridomicilio, en muchas ocasiones puede dormir, cazar y alimentarse de carne de animales silvestres infectados, en las áreas selváticas pericomunitarias. Dado que su expectativa de vida es corta, la existencia de caninos seropositivos indican la existencia de transmisión activa de la enfermedad, lo cual implica que los caninos sirven como centinelas de la transmisión, permitiendo monitorear la transmisión de la enfermedad de Chagas en el pasado más reciente 9,10 .

Rhodnius prolixus ha representado desde el punto de vista parasitológico, epidemiológico y de salud pública el vector más importante para la transmisión de la enfermedad de Chagas en Venezuela, es un vector con hábitos predominantemente intradomiciliarios, encontrándose también adaptado al peridomicilio y medio silvestre 11,12. En las últimas décadas, debido a la implementación de programas intensivos de eliminación del vector a través del rociamiento con insecticidas residuales y la substitución de las viviendas, los niveles de infestación en casas por este vector han disminuido significativamente ${ }^{3}$.

Triatoma maculata y Panstrongylus geniculatus han sido considerados vectores secundarios de importancia limitada en la transmisión de la enfermedad de Chagas. P. geniculatus ha sido encontrado más frecuentemente en el medio silvestre 13,14; ocasionalmente se ha encontrado domiciliado asociado a Rattus rattus $15 \mathrm{y}$ recientemente ha sido encontrado infectado por Tr. cruzi en el interior de domicilios en el Estado Lara 8,16 .

Por otra parte, T. maculata ha sido encontrado infectado naturalmente con Tr. cruzi y está adaptado preferentemente al peridomicilio y medio silvestre 17 . Se encuentra con frecuencia en áreas costeras y en regiones xerófilas de Venezuela, es considerada una especie primariamente ornitófaga, especialmente asociada a gallinas y palomas en el hábitat peridomiciliario 18 . Estudios previos en Venezuela han descrito viviendas infestadas por T. maculata en áreas endémicas para la enfermedad de Chagas; así Gamboa \& Pérez-Ríos (1964, apud Tonn et al. 17) encontraron índices de infestación de 4,5\% y 9,2\%, en los estados Miranda y Guárico, respectivamente; mientras que Tonn et al. 17, en 1978, en estudios realizados en 14 estados de Venezuela, reportaron índices de infestación domiciliaria y peridomiciliaria del $0,8 \%$ y $2,7 \%$, respectivamente.

El papel del T. maculata en la transmisión de la enfermedad de Chagas es difícil de evaluar, debido a la limitada literatura actualizada existente sobre el tema (la publicación más reciente en Venezuela se remonta a 1978) y debido a índices de infestación e infección, inferiores a los índices reportados para $R$. prolixus ${ }^{17}$. Este concepto es respaldado por una investigación realizada en Passarão (Estado de Roraima, Brasil) en un área infestada por T. maculata, donde se observó que los pobladores autóctonos fueron seronegativos 19. Como contraste, recientemente en Talaigua Nueva (Departamento de Bolívar, Colombia) se ha reportado un caso agudo y casos seropositivos para la enfermedad de Chagas en niños menores a 9 años, epidemiológicamente asociados a la presencia de T. maculata, con índices de infestación en el domicilio del $20 \%$, de colonización 38,3\% y de infección natural $58,33 \%$, indicando que $T$. maculata podría ser considerado un vector eficiente en la transmisión de la enfermedad de Chagas 20 .

En el presente trabajo se realiza un estudio seroepidemiológico en humanos y caninos, y una encuesta entomológica en un área geográfica donde ha sido reportada la presencia de T. $m a$ culata, con el objetivo de establecer los factores de riesgo asociado a la presencia de este vector en las comunidades sujeto de estudio, determinar su papel en la transmisión de la enfermedad de Chagas y establecer si existe transmisión activa de la enfermedad de Chagas en el pasado más reciente. 


\section{Materiales y métodos}

\section{Área de estudio}

El estudio se realizó en la parroquia Xaguas, del municipio Urdaneta, Estado Lara, Venezuela, ubicada a una latitud N 10³7'10", una longitud O 6958'58", a una altitud 395 metros sobre el nivel del mar, con clima continental estacional y temperaturas que oscilan entre los $27^{\circ} \mathrm{C}$ y $39^{\circ} \mathrm{C}$, con suelos xerosoles, pluviosidad en 4 años de $527,8 \mathrm{ml}$ y una vegetación de tipo espinar. Las actividades humanas predominantes en la zona son la agricultura y la cría de caprinos. Los cultivos más frecuentes son melón, cebolla, sorgo, pimentón y sábila. Se calcula que existen alrededor de 100 mil caprinos en el Municipio, los cuales son criados libres en el medio silvestre.

La parroquia cuenta con una población de 3.116 habitantes, siendo el 42,7\% menores de 15 años de edad. Fueron escogidas intencionalmente para el estudio la capital de la parroquia Xaguas Baragua y las comunidades de La Concordia, La Estación, Arenales y El Hato, situadas en el área de influencia de los ambulatorios de salud de Baragua y el Hato. El área de estudio cuenta con 1.518 habitantes y 414 viviendas.

\section{Estudio epidemiológico}

La unidad de muestreo fueron las viviendas, seleccionadas por conglomerados no estratificados a partir de mapas actualizados del área. Se asumió un nivel de confianza del 99\%, un error máximo admisible de 2,03\% y una prevalencia previa del 5\%. La muestra quedó representada por 140 viviendas: Baragua 94, La Concordia 17, La Estación 7, Arenales 10 y El Hato 12. Los criterios de inclusión de los habitantes de las viviendas seleccionadas, fueron basados en las normas del Comité de Ética del Decanato de Medicina de la Universidad Centroccidental "Lisandro Alvarado", en concordancia con la Declaración de Helsinki de la Asociación Médica Mundial, con los siguientes criterios de inclusión: ser residentes permanentes de la vivienda, sin discriminación de sexo o edad, que aceptaran de manera voluntaria, por consentimiento escrito o á través de sus representantes participar en el estudio. Se incluyeron los cánidos de las viviendas seleccionadas, que fueran lo suficientemente dóciles para permitir los procedimientos experimentales y previa autorización de los dueños. En total se estudiaron 509 personas, 229 del género masculino y $280 \mathrm{del}$ femenino, además de 110 cánidos. En cada vivienda se aplicó una encuesta epidemiológica para la obtención de datos demográficos, iden- tificación de factores de riesgo y conocimientos sobre la enfermedad de Chagas.

\section{Diagnóstico serológico y parasitológico}

Por venopunción se extrajeron de 5 a $7 \mathrm{ml}$ de sangre a cada individuo humano o canino, a partir del cual se obtuvo por centrifugación el suero. El suero se alicuotó por duplicado y fue transportado a $2-5^{\circ} \mathrm{C}$ hasta el laboratorio central, donde se almacenó a $-70^{\circ} \mathrm{C}$ hasta su procesamiento.

La determinación de anticuerpos anti-Tr. cruzi en el suero fue realizada mediante las técnicas de ELISA (enzyme-linked immunoabsorbent assay) 21 y MABA (multiple antigen blot assay 22, ensayo de inmunoblot de tres bandas), utilizando los antígenos recombinantes PGR31His, PGR30-His y PGR24-His de Tr. cruzi y anticuerpos secundarios tipo anti-IgG humana o canina específicas para la cadena $\gamma$, conjugada a la enzima peroxidasa (Sigma Chemical Co.). Los antígenos recombinantes utilizados representan secuencias peptídicas codificadas, específicamente por el genoma del Tr. cruzi, lo cual le permite a la prueba tener un $100 \%$ de especificidad. La utilización de tres antígenos permite alcanzar una sensibilidad superior al 95\%.

El MABA fue considerado positivo cuando al menos dos de las tres bandas de los antígenos recombinantes fuesen visibles. Las muestras se consideraron positivas sólo si ambas pruebas ELISA y MABA resultasen reactivas y negativas si una o ambas pruebas fuesen no reactivas.

\section{Estudio entomológico}

La recolección de triatominos se realizó a través de: (a) la búsqueda pasiva realizada por los habitantes de las comunidades, a quienes se les entregó envases y se entrenaron para recolectar los especímenes en la vivienda o en el peridomicilio; (b) la revisión sistemática de la vivienda y peridomicilio, por dos miembros del equipo de investigación, por espacio de una hora, utilizando pinzas largas, linternas e insecticidas como excitantes. Los triatominos capturados se clasificaron según clave de Lent \& Wygodzinsky ${ }^{13}$. El contenido de la porción distal del intestino del insecto se diluyó en solución salina 0,9\% y se estudió mediante microscopía óptica en búsqueda del Tr. cruzi, el cual fue identificado por sus características morfológicas. Además, se implementó la detección de $\mathrm{ADN}$ parasitario a través de la técnica de PCR, a partir de homogenizados de la región distal del abdomen del triatomino, utilizando los iniciadores 189Fw2/189Rv3 23.

De los resultados obtenidos se calcularon los siguientes índices vectoriales: Infestación, Colo- 
nización, Coinfestación, Infección y Dispersión, en concordancia con criterios establecidos por la Organización Mundial de la Salud (OMS) en el año 2002.

\section{Análisis de los datos}

Los datos son presentados en valores absolutos, porcentuales e índices numéricos. Con el fin de evaluar las relaciones existentes entre factores de riesgo epidemiológico para la enfermedad de Chagas y la presencia del vector en el domicilio y/o en el peridomicilio, se realizó un análisis de regresión logística binaria, utilizando el programa SPSS, versión 11.0.1 (SPSS Inc., Chicago, Estados Unidos). Las variables fueron categóricas y dicotómicas (presencia o ausencia), las variables dependientes fueron presencia de T. maculata adulto en el domicilio, presencia del T. macula$t a$ adulto en el peridomicilio, presencia de estadios ninfales en el domicilio y presencia de estadios ninfales en el peridomicilio. Las variables independientes fueron clasificadas en aquellas consideradas fuentes de alimento y/o reservorio (presencia o ausencia de perros, gatos, caprinos, gallinas, roedores o murciélagos) y aquellas relacionadas con características físico-culturales del domicilio y del peridomicilio (vivienda consolidada o no consolidada; distribución adecuada o inadecuada del domicilio y peridomicilio; presencia o ausencia de desorden en el domicilio o en el peridomicilio; y presencia o ausencia de gallineros o corrales para mamíferos en el peridomicilio).

\section{Resultados}

De los 509 individuos estudiados, se encontraron 8 individuos con anticuerpos anti-Tr. cruzi detectados por ELISA y MABA, lo cual representa una prevalencia general de $1,57 \%$, de los cuales $6(75 \%)$ eran del sexo masculino y 2 (25\%) del femenino. Todos los seropositivos fueron mayores de 15 años, estando el mayor número de seropositivos en mayores de 60 años $(n=3)$. La prevalencia en los sectores estudiados fue de 1,3\% en Baragua y 4,93\% en El Hato, mientras que en La Concordia, Arenales y La Estación no se encontraron individuos seropositivos (Tabla 1).

De los 110 cánidos muestreados, se encontraron 7 con anticuerpos anti-Tr. cruzi positivos detectados con ELISA y MABA, para una prevalencia general de $6,36 \%$, ubicándose el mayor número de seropositivos entre los rangos de edades de 2 a 3 años y de 6 a 7 años, no hubo casos seropositivos en cánidos mayores de 10 años y en menores de 1 año de edad. La prevalencia en los sectores estudiados fue $6,77 \%, 0,1 \%$ y $9,52 \%$ en Baragua, Arenales y El Hato, respectivamente; no encontrándose casos seropositivos en La Concordia y La Estación (Tabla 2).

Se capturaron un total de 545 triatominos, de los cuales el 97,98\% eran especímenes que pertenecían a la especie T. maculata, capturados predominantemente en el peridomicilio, 1,65\% de los especímenes capturados correspondió a Eratyrus mucronatus predominantemente capturados en el domicilio y $0,36 \%$ P. geniculatus capturados dentro del domicilio (Tabla 3).

Tabla 1

Distribución de seroprevalencia para anticuerpos anti-Trypanosoma cruzi en la población humana, según edad y sectores estudiados de la parroquia Xaguas, municipio Urdaneta, Estado Lara, Venezuela.

\begin{tabular}{|c|c|c|c|c|c|c|c|c|c|c|c|c|c|c|}
\hline \multirow{4}{*}{$\begin{array}{l}\text { Rango } \\
\text { de edad } \\
\text { (años) }\end{array}$} & \multicolumn{12}{|c|}{ Sectores } & \multirow{4}{*}{$\begin{array}{l}\text { Prevalencia } \\
\text { específica } \\
\text { por edad * }\end{array}$} & \multirow{4}{*}{$\begin{array}{c}\text { Prevalencia } \\
\text { general por } \\
\text { edad } \star \star\end{array}$} \\
\hline & \multirow{2}{*}{\multicolumn{2}{|c|}{ Baragua }} & \multirow{2}{*}{\multicolumn{2}{|c|}{$\begin{array}{c}\text { La } \\
\text { Concordia }\end{array}$}} & \multirow{2}{*}{\multicolumn{2}{|c|}{$\begin{array}{l}\text { La } \\
\text { Estación }\end{array}$}} & \multirow{2}{*}{\multicolumn{2}{|c|}{ Arenales }} & \multirow{2}{*}{\multicolumn{2}{|c|}{$\begin{array}{c}\text { El } \\
\text { Hato }\end{array}$}} & \multirow{2}{*}{\multicolumn{2}{|c|}{ Total }} & & \\
\hline & & & & & & & & & & & & & & \\
\hline & + & - & + & - & + & - & + & - & + & - & + & - & & \\
\hline $0-9$ & 0 & 41 & 0 & 19 & 0 & 4 & 0 & 13 & 0 & 18 & 0 & 95 & 0,00 & 0,00 \\
\hline $10-19$ & 0 & 72 & 0 & 16 & 0 & 3 & 0 & 4 & 1 & 14 & 1 & 108 & 0,91 & 0,20 \\
\hline $20-29$ & 0 & 51 & 0 & 11 & 0 & 3 & 0 & 7 & 1 & 16 & 1 & 87 & 1,13 & 0,20 \\
\hline $30-39$ & 0 & 48 & 0 & 13 & 0 & 2 & 0 & 6 & 0 & 10 & 0 & 79 & 0,00 & 0,00 \\
\hline $40-49$ & 1 & 39 & 0 & 5 & 0 & 2 & 0 & 2 & 0 & 2 & 1 & 50 & 1,96 & 0,20 \\
\hline $50-59$ & 2 & 17 & 0 & 2 & 0 & 0 & 0 & 2 & 0 & 5 & 2 & 26 & 7,14 & 0,39 \\
\hline$>60$ & 1 & 35 & 0 & 6 & 0 & 3 & 0 & 2 & 2 & 12 & 3 & 56 & 5,08 & 0,59 \\
\hline Total & 4 & 303 & 0 & 72 & 0 & 17 & 0 & 36 & 4 & 77 & 8 & 501 & 1,57 & 1,57 \\
\hline
\end{tabular}

* Prevalencia específica para cada rango de edad se refiere al porcentaje de seropositivos de cada rango de edad, respecto a la población de cada rango;

** Prevalencia general por edad se refiere al porcentaje de seropositivos de cada rango de edad, respecto a la población general. Aplicando la prueba de chi-cuadrado para analizar la presencia o ausencia de seropositivos de acuerdo a la edad encontramos un valor de $F=13,56$ y $p=0,039$. 
Distribución de seroprevalencia para anticuerpos anti-Trypanosma cruzi en la población canina, según edad y sectores estudiados de la parroquia Xaguas, municipio Urdaneta, Estado Lara, Venezuela.

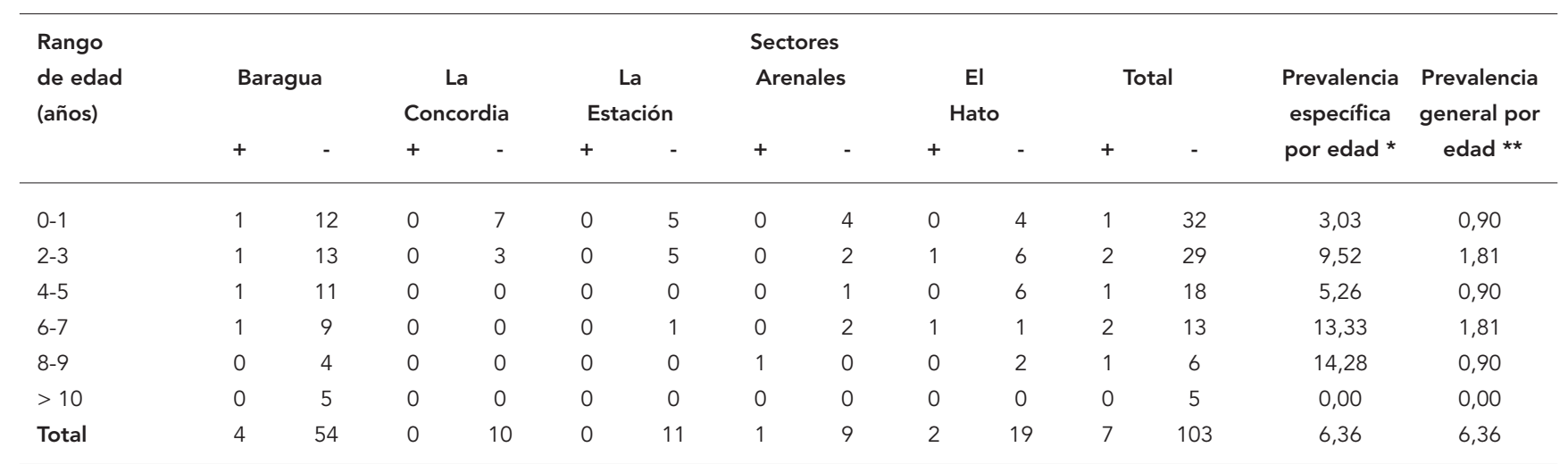

* Prevalencia específica para cada rango de edad se refiere al porcentaje de seropositivos de cada rango de edad, respecto a la población de cada rango;

** Prevalencia general por edad se refiere al porcentaje de seropositivos de cada rango de edad, respecto a la población general. Aplicando la prueba de chi-cuadrado para analizar la presencia o ausencia de seropositivos de acuerdo a la edad encontramos un valor de $\mathrm{F}=2,954$ y $\mathrm{p}=0,707$.

Tabla 3

Distribución de las especies de triatominos capturados.

\begin{tabular}{|c|c|c|c|c|c|c|}
\hline \multirow[t]{2}{*}{ Triatominos } & \multicolumn{2}{|c|}{ Peridomicilio } & \multicolumn{2}{|c|}{ Domicilio } & \multicolumn{2}{|c|}{ Total } \\
\hline & Ninfas & Adultos & Ninfas & Adultos & Ninfas & Adultos \\
\hline Triatoma maculata & 303 & 106 & 15 & 110 & 318 & 216 \\
\hline Panstrongylus geniculatus & 0 & 0 & 0 & 2 & 0 & 2 \\
\hline Eratyrus mucronatus & 0 & 1 & 0 & 8 & 0 & 9 \\
\hline Total & 303 & 107 & 15 & 120 & 318 & 227 \\
\hline
\end{tabular}

De las 140 viviendas encuestadas, en 23 se encontraron triatominos dentro del domicilio, en 17 se encontraron triatominos en el peridomicilio; en 9 domicilios y en 9 peridomicilios se recolectaron ninfas, huevos y/o exuvias ninfales, y en 2 viviendas cohabitaban dos especies de triatominos. En 2 ejemplares de T. maculata se detectó ADN parasitario a través de la técnica de PCR (Figura 1), mientras que el análisis microscópico de las deyecciones de T. maculata, P. geniculatus y $E$. mucronatus no demostró la presencia de formas parasitarias flagelares similares a Tr. cruzi. La Tabla 4 muestra los índices vectoriales calculados a partir de los datos recolectados.

Los factores de riesgo para la infestación del domicilio y el peridomicilio más frecuentemente observados fueron la vivienda no consolidada, la presencia de perros en la vivienda, la presencia de roedores en la vivienda y el desorden en el domicilio y/o en el peridomicilio (Tabla 5), sin embargo, al contrastar la presencia o ausencia de un factor de riesgo con la presencia o ausencia de infestación en la vivienda, los resultados mostraron lo siguiente en relación con las fuentes de alimento y/o reservorios: (1) la presencia de vectores adultos en el domicilio se asocia a la presencia de gallinas, las cuales representan un factor de riesgo ( $\mathrm{B}=1,449$; IC95\%: 1,35-13,42; $\mathrm{p}=0,013$ ); (2) la presencia de estadios ninfales en el domicilio y en el peridomicilio estuvo asociada a la presencia de caprinos, los cuales representaron un factor de riesgo $(\mathrm{B}=1,72$; IC95\%: 1,147-27,45; $\mathrm{p}=0$ 0,033 y B = 2,58; IC95\%: 1,799-97,28; $p=0,011$, respectivamente); (3) no se observó ninguna asociación estadísticamente significativa entre la presencia del vector en el domicilio y peridomicilio con la presencia de perros, gatos, roedores y murciélagos.

En relación a las características físico culturales del domicilio y peridomicilio, los resulta- 
Figura 1

Detección del genoma parasitario por PCR.

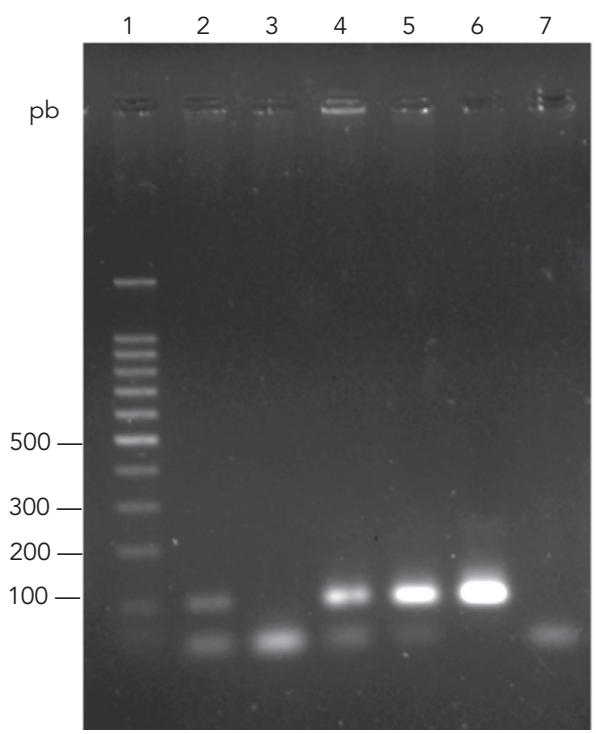

Nota: la columna 1 muestra el marcador de peso molecular en escala ascendente de 100 pares de base (pb); las columnas 2, 3 y 4 corresponden a muestras de ADN del contenido intestinal de triatominos capturados en los sectores; la columna 5 corresponde al ADN del contenido intestinal de un triatomino control positivo infectado y criado en el laboratorio; la columna 6 representa un control positivo, correspondiente al transcrito del ADN de Trypanosoma cruzi, mediante la metodología descrita y la columna 7 representa un control negativo. dos mostraron: (1) la presencia de gallineros en el peridomicilio representan un factor de riesgo para la presencia de estadios ninfales $(\mathrm{B}=3,72$; IC95\%: 3,51-485,29; $\mathrm{p}=0,003$ ) y estadios adultos (B = 1,56; IC95\%: 1,203-18,79; $\mathrm{p}=0$ 0,026) del $T$. maculata en el peridomicilio; (2) el desorden peridomiciliario es un factor protector $(\mathrm{B}=-1,497$; IC95\%: 0,06-0,829; $p=0,025$ ) que evita la presencia de formas adultas del vector en el domicilio; (3) la distribución adecuada del domicilio es un factor protector que evita la presencia de ninfas en el domicilio ( $\mathrm{B}=-4,58$; IC95\%: 0,000-0,681; $\mathrm{p}$ = 0,032); (4) no se observó ninguna asociación estadísticamente significativa entre la presencia del vector en el domicilio y peridomicilio con el tipo de vivienda, con la presencia de corrales en el peridomicilio, con el desorden intradomiciliario o con la distribución adecuada del peridomicilio.

\section{Discusión}

En el presente trabajo se realizó por primera vez en Venezuela un estudio seroepidemiológico en humanos y caninos y una encuesta entomológica en una región infestada por T. maculata, lográndose obtener datos que permiten apoyar la noción que T. maculata tiene la capacidad de colonizar el domicilio y podría ser el vector responsable de la transmisión de la enfermedad de Chagas en el área estudiada.

Tabla 4

Índices entomológicos de triatominos capturados.

\begin{tabular}{lccc}
\hline Índice & Población de referencia total & Población afectada & Índice (\%) \\
\hline Índice de infestación & $140 *$ & $23 * *$ & 16,42 \\
Índice de colonización & $23 * *$ & $9 * *$ & 39,13 \\
Índice de coinfestación & $23 * *$ & $2 \#$ & 2 \#\#\# \\
Índice de infección del vector & $545 \# \#+63$ \\
Índice de infección domiciliaria & $23 * *$ & $1 \S$ & 0,36 \\
Índice de dispersión & $5 \S \S$ & $5 \S \S$ & 4,34 \\
\hline
\end{tabular}

Los superíndices significan:

* Número de viviendas encuestadas;

** Número de viviendas con vectores domiciliarios;

*** Número de viviendas con ninfas y/o huevos domiciliarios;

\# Número de viviendas con más de una especie de triatomino domiciliario;

\#\# Vectores capturados;

\#\# Número de vectores positivos a Tr. cruzi;

$\S$ Número de viviendas con triatominos infectados con Tr. cruzi;

$\S \S$ Número de sectores estudiados;

$\S \S \S$ Número de sectores donde se capturaron vectores. 
Frecuencia de factores de riesgo asociados a la presencia o ausencia del vector en el domicilio y peridomicilio.

\begin{tabular}{|c|c|c|c|c|c|c|c|c|c|c|c|c|}
\hline \multirow[t]{4}{*}{ Factor de riesgo } & \multicolumn{2}{|c|}{ Frecuencia } & \multicolumn{5}{|c|}{ Domicilio } & \multicolumn{5}{|c|}{ Peridomicilio } \\
\hline & \multirow[t]{3}{*}{$\mathbf{n}$} & \multirow[t]{3}{*}{$\%$} & \multirow{2}{*}{\multicolumn{2}{|c|}{$\begin{array}{c}\text { Vector } \\
\text { presente }\end{array}$}} & \multirow{2}{*}{\multicolumn{2}{|c|}{$\begin{array}{l}\text { Vector } \\
\text { ausente }\end{array}$}} & \multirow[t]{3}{*}{ P/A } & \multirow{2}{*}{\multicolumn{2}{|c|}{$\begin{array}{l}\text { Vector } \\
\text { Presente }\end{array}$}} & \multirow{2}{*}{\multicolumn{2}{|c|}{$\begin{array}{l}\text { Vector } \\
\text { Ausente }\end{array}$}} & \multirow[t]{3}{*}{$\mathrm{P} / \mathrm{A}$} \\
\hline & & & & & & & & & & & & \\
\hline & & & $\mathrm{n}$ & $\%$ & $\mathrm{n}$ & $\%$ & & $\mathrm{n}$ & $\%$ & $\mathrm{n}$ & $\%$ & \\
\hline Vivienda no consolidada & 71 & 50,71 & 13 & 56,52 & 58 & 49,57 & 1,14 & 13 & 76,47 & 58 & 47,15 & 1,62 \\
\hline Perros & 75 & 53,57 & 17 & 73,91 & 58 & 49,57 & 1,49 & 10 & 58,82 & 65 & 52,86 & 1,11 \\
\hline Gatos & 43 & 30,71 & 4 & 17,39 & 39 & 33,33 & 0,52 & 6 & 35,29 & 37 & 30,08 & 1,17 \\
\hline Caprinos y/u ovinos & 32 & 22,87 & 8 & 34,78 & 24 & 20,51 & 1,70 & 8 & 47,06 & 24 & 19,51 & 2,44 \\
\hline Gallinas & 63 & 45 & 16 & 69,56 & 47 & 40,17 & 1,73 & 12 & 70,58 & 51 & 41,46 & 1,70 \\
\hline Roedores & 79 & 56,42 & 14 & 60,86 & 65 & 55,55 & 1,10 & 11 & 64,70 & 68 & 55,28 & 1,17 \\
\hline Murciélagos & 38 & 27,14 & 5 & 21,74 & 33 & 28,20 & 0,77 & 8 & 47,05 & 30 & 24,39 & 1,93 \\
\hline Distribución adecuada del domicilio & 102 & 72,86 & 13 & 56,52 & 89 & 76,06 & 0,74 & 7 & 41,17 & 95 & 77,24 & 0.53 \\
\hline Desorden domiciliario & 72 & 51,43 & 9 & 52,94 & 63 & 51,21 & 1,03 & 12 & 70,59 & 60 & 48,78 & 1,45 \\
\hline Distribución adecuada del peridomicilio & 92 & 65,71 & 14 & 60,87 & 78 & 66,66 & 0,91 & 8 & 47,06 & 84 & 68,29 & 0,69 \\
\hline Desorden del peridomiclio & 80 & 57,14 & 6 & 35,29 & 74 & 60,16 & 0,59 & 12 & 70,59 & 68 & 55,28 & 1,28 \\
\hline Anexos de bahareque & 47 & 33,57 & 6 & 26,09 & 41 & 35,04 & 0.74 & 10 & 58,82 & 37 & 30,08 & 1,96 \\
\hline Gallineros & 25 & 17,85 & 4 & 17,39 & 21 & 17,94 & 0,97 & 7 & 41,17 & 18 & 14,63 & 2,81 \\
\hline Corrales & 27 & 19,28 & 6 & 26,09 & 21 & 17,95 & 1,45 & 6 & 35,29 & 21 & 17,07 & 2,07 \\
\hline
\end{tabular}

P/A: Índice Vector Presente/Vector Ausente.

Nota: domicilios infestados $=23$; peridomicilios infestados $=17$; número de viviendas encuestadas $=140$.

En el presente trabajo se reportan índices de infestación y colonización del domicilio por $T$. maculata superiores a los índices de infestación observados en Venezuela para este vector en la década de los años 60 y 70, cuando se observaron índices entre el 0,8 y el 9,2\% 17 . Resultados similares han sido reportados en Talaigua Nueva (Bolívar, Colombia), donde se observaron índices de infestación y de colonización del 20 y 38,3\%, respectivamente 20 .

Estos estudios evidencian la capacidad que tiene el T. maculata de infestar y colonizar la vivienda humana y que la población de este vector con capacidad de invadir el domicilio ha sufrido un incremento en las últimas décadas en Venezuela. Contrastando con estos resultados, en Passarão (Roraima, Brasil) no se observaron ninfas, huevos o exuvias en el domicilio ${ }^{19}$, indicando que la capacidad de T. maculata de domiciliarse podría depender de sus características genéticas y de las características ecológicas presentes en las áreas infestadas por el vector.

En Venezuela T. maculata ha sido encontrado naturalmente infectado con bajos índices de infección que han oscilado entre el 0 y el $1 \% 17$, resultados similares han sido reportados en Roraima (Brasil) 19 y en el presente trabajo. Los bajos índices de infección podrían estar asociados con los hábitos alimentarios del vector, quien tie- ne conocida preferencia ornitofílica y cuyo éxito reproductivo está condicionado a la ingesta de sangre de aves, lo que explicaría su hábitat preferentemente peridomiciliario ${ }^{18}$. Este punto de vista es sustentado por estudios experimentales realizados con ninfas de $\mathrm{V}$ estadio, alimentadas con sangre humana, las cuales no fueron capaces de mudar a etapa adulta, indicando una dificultad de esta especie para la adaptación a largo plazo al domicilio humano 24.

Contrastando con los resultados descritos anteriormente, un elevado índice de infección a $T r$. cruzi para T. maculata $(58,33 \%)$ ha sido reportado en Talaigua Nuevo (Bolívar, Colombia), en especímenes capturados predominantemente en el ambiente domiciliario, donde se logró demostrar que este vector realizó un ciclo intradomiciliario 20. Estos resultados indican que T. maculata puede adaptarse a tener como fuentes de alimento los mamíferos encontrados en el domicilio. Esta inferencia es sostenida con datos obtenidos bajo condiciones de laboratorio, donde se observó que cuando especímenes de T. maculata se alimentan de sangre de mamíferos, su potencial de vida y vectorial se ven favorecidos 25 .

Los resultados contradictorios, observados entre estudios realizados con triatominos provenientes de diferentes áreas geográficas, sugieren que presiones ambientales y ecológicas diferen- 
tes han conducido a adaptaciones distintas en las poblaciones de T. maculata, lo cual podría impactar la capacidad vectorial del insecto 25 .

Los bajos índices de infección a Tr. cruzi del T. maculata y la baja seroprevalencia en humanos observada en este trabajo, podría indicar una limitada capacidad vectorial del T. maculata en la región estudiada, dejando la posibilidad que los humanos seropositivos encontrados podrían ser inmigrantes de áreas endémicas infestadas por vectores más eficientes, como ha sido reportado en Passarão (Roraima, Brasil) 19. Tomando en consideración lo siguiente: (a) que los 8 individuos seropositivos encontrados en este trabajo son individuos autóctonos de la región objeto de estudio, de los cuales 6 eran individuos mayores de 40 años y 2 individuos menores a 30 años; (b) basados en estudios realizados por Cova-García \& Suárez 26, donde se reportó en la década del 1950 a 1960 la presencia de $R$. prolixus y T. maculata en el área objeto de estudio; (c) que en el año 1966 se inició el establecimiento de programas exitosos de rociamiento de viviendas con insecticidas de acción residual y sustitución del rancho por vivienda 27 , podemos sugerir que los dos casos observados en menores de 30 años, deberían ser atribuidos al T. maculata como vector, no obstante, otras formas de transmisión podrían estar involucradas, lo cual no fue posible valorar estadísticamente en este trabajo por el bajo número de humanos seropositivos.

Llama la atención en este trabajo el hallazgo intradomiciliario de formas adultas de especies descritas como silvestres (P. geniculatus y E. $m u$ cronatus). La infestación y colonización del domicilio humano por P. geniculatus 8,15,16 y E. mucronatus 28 ha sido documentada recientemente en Venezuela, lo cual sustenta la noción de un cambio en la dinámica adaptativa de las especies de vectores asociados a la enfermedad de Chagas en este país. Estos cambios son producto de alteraciones en los ecosistemas localizados en las áreas endémicas para la enfermedad de Chagas, donde la deforestación y caza de la fauna silvestre han impactado el hábitat natural y las fuentes de alimentación de los triatominos silvestres, presionando la migración y adaptación a los hábitats donde se desarrollaron los programas de eliminación del $R$. prolixus.

Otro punto relevante de este estudio fue la prevalencia de anticuerpos séricos anti-Tr. cruzi en cánidos, con una prevalencia del $6,36 \%$, la cual es similar a estudios realizados en zonas endémicas de Costa Rica (5,2\% al 9,9\%) 29,30 y Estados Unidos (3,6\% al 7,5\%) 31,32, sin embargo, prevalencias ampliamente superiores han sido reportadas en áreas rurales de Venezuela $(67,6 \%) 33$ y de Argentina ( $83 \%$ y 40\%, antes y 3 años después de la aplicación de insecticidas) 34 .

Las altas prevalencias en perros podrían estar asociadas a la presencia de casos agudos en humanos 6,33 y a altas prevalencias de individuos infectados en el domicilio asociadas a altos niveles de infección triatomínica 34 , lo cual podría sugerir que el humano por su mayor expectativa de vida, sería el reservorio responsable de la alta prevalencia de la infección en los caninos. Por otra parte, la presencia y el número de vectores infectados en la vivienda se ha asociado a la presencia de cánidos infectados con Tr. cruzi 34 .

Cuando los niveles de seroprevalencia en humanos son bajos, el perro por sus hábitos biológicos y conductuales actúa como indicador o centinela de la existencia de transmisión activa de la enfermedad en las áreas controladas 9,10. El hecho de que en este estudio, un canino seropositivo tenía un año de edad, documenta y sitúa temporalmente el último momento cuando ocurrió la transmisión de la infección en el área.

En el medio rural el canino es un animal que no es estático, sin embargo, su capacidad de desplazamiento entre comunidades aisladas geográficamente, es prácticamente nula, sugiriendo que los casos observados en este trabajo son autóctonos.

Los mecanismos de transmisión involucrados en la transmisión del Tr. cruzi en los caninos en el presente trabajo podrían haber sido: vectorial, digestiva, vertical u horizontal de cánido a cánido ${ }^{34}$, sin embargo, al realizar los análisis estadísticos no encontramos una correlación significativa $\left(\chi^{2}\right.$ con $\left.\mathrm{p}>0,05\right)$ entre la seropositividad en cánidos con el hábito de comer carne cruda o de alimentarse de animales silvestres; adicionalmente no observamos seropositividad en animales menores a un año descartando la transmisión congénita, dejando entonces con mayor probabilidad la transmisión vectorial, lo cual coincide con la relación que hubo en cuanto a la seropositividad en perros y humanos con áreas geográficas donde se observaron casos positivos (Baragua y El Hato).

Los factores de riesgo encontrados en este trabajo, asociados a la presencia del vector en el domicilio o en el peridomicilio con significado estadístico fueron la presencia de gallinas, caprinos y gallineros, sugiriendo que estos animales podrían ser fuentes de alimento o podrían emitir substancias atrayentes al vector, sin embargo, a pesar de favorecer la presencia del vector, también es cierto que siendo especialmente las aves especies refractarias al parásito, representarían barreras biológicas que limitarían la infección por Tr. cruzi del vector, siempre y cuando la población triatomínica no 
sobrepase la disponibilidad de fuentes alimentarias avícolas. Como factores protectores a la presencia de vectores en la vivienda estuvieron la adecuada distribución del domicilio y el desorden peridomiciliario, los cuales facilitarían la infestación del peridomicilio en detrimento del domicilio. En este sentido, De Andrade et al. 35, al comparar características de construcción y del ambiente de casas infestadas y no infestadas por Triatoma infestans, encontraron que la presencia del vector en el domicilio se asocia a casas con construcción incompleta, a la presencia de ratas y a la presencia de depósitos para cosechas en el domicilio 35 , mientras que Feliciangeli et al. 36 en un estudio realizado en el estado Barinas en Venezuela, región infestada predominante por $R$. prolixus, encontró como factores de riesgo asociados a la infestación del domicilio el número de residentes y hacinamiento en la vivienda y la presencia de trojas en el peridomicilio 36 .

En conclusión, en el área estudiada existe un ciclo de transmisión activa de enfermedad de Chagas en los cánidos, mientras en humanos la transmisión esta interrumpida a corto plazo, asimismo, este trabajo sugiere que T. maculata posee capacidad de colonizar el domicilio y actualmente es responsable en bajo grado de la transmisión de la enfermedad de Chagas en esta área.

\section{Resumen}

En el presente trabajo se realizó un estudio seroepidemiológico, entomológico y de factores de riesgo para la infestación de las viviendas en un área infestada por Triatoma maculata (Parroquia Xaguas, Municipio Urdaneta, Estado Lara, Venezuela). Se muestrearon 140 viviendas, 509 personas y 110 cánidos, a los cuales se les determinó anticuerpos séricos anti-Trypanosoma cruzi mediante ELISA y MABA, utilizando antígenos recombinantes. La infección por Tr. cruzi de los triatominos fue determinada por microscopía óptica y PCR. Los resultados mostraron una seroprevalencia en humanos de 1,57\% y en cánidos de 6,36\%. De los 545 triatominos capturados $97,98 \%$ fueron $\mathrm{T}$. maculata, 1,65\% Eratyrus mucronatus y 0,37\% Panstrongylus geniculatus; con índices vectoriales de infección 0,36\%, infestación 16,4\%, colonización 39,1\%, coinfestación 8,6\% y dispersión 100\%. La presencia de vectores en el domicilio y peridomicilio estuvo asociada a la presencia de gallinas, desorden en el peridomicilio, caprinos, gallineros y/o distribución del domicilio. Los resultados permiten concluir que T. maculata es el vector predominante en la región, con capacidad de infestar y colonizar el domicilio y estaría involucrado en la transmisión de la enfermedad de Chagas.

Triatoma maculata; Trypanosoma cruzi; Enfermedad de Chagas; Factores de Riesgo

\section{Colaboradores}

M. E. Rojas, P. Várquez, M. F. Villarreal, C. Velandia y L. Vergara participaron en la adquisición de los datos epidemiológicos mediante trabajo de campo, participaron en el análisis de los datos mediante la creación de la base de datos para el análisis estadístico especializado. Y. H. Morán-Borges y M. A. Chiurillo-Siervo contribuyeron en el diseño, montaje e interpretación del PCR para detección del ADN parasitario. J. Ontiveros realizó el análisis estadístico. M. Y. Calderón y E. Aldana contribuyeron a la concepción y diseño de la estrategia de la recolección de los triatominos y fueron responsables de la identificación y clasificación de los especimenes capturados. J. L. Concepción desarrolló los antígenos recombinantes, ensambló, montó e interpretó las pruebas inmunodiagnósticas. C. C. Rodríguez-Bonfante y R. A. Bonfante-Cabarcas participaron en la concepción, diseño y dirección del trabajo global, en la recolección de datos epidemiológicos, mediante el trabajo de campo, en el análisis e interpretación de los datos y en la concepción y redacción del manuscrito. Todos los autores participaron en la revisión crítica del manuscrito y aprobaron la versión final para su publicación.

\section{Agradecimientos}

Estudio financiado por la Alcaldía del Municipio Urdaneta, Estado Lara, por el Programa de Promoción a la Investigación (PPI) como parte del Proyecto Integral de Chagas registrado en Consejo de Desarrollo Científico, Humanístico y Tecnológico (CDCHT) de la Universidad Centroccidental Lisandro Alvarado (UCLA) y por la Misión Ciencia, Ministerio del Poder Popular para la Ciencia y Tecnología, Fondo Nacional de Ciencia y Tecnología (FONACIT, proyecto no. 2007001425). 


\section{Referencias}

1. Moncayo A. Chagas' disease: current epidemiological trends after the interruption of vectorial and transfusional transmission in the southern cone countries. Mem Inst Oswaldo Cruz 2003; 98:577-91.

2. Aché A. Programa de control de la enfermedad de Chagas en Venezuela. Bol Dir Malariol Saneam Ambient 1993; 33:11-22.

3. Aché A, Matos AJ. Interrupting Chagas' disease transmission in Venezuela. Rev Inst Med Trop São Paulo 2001; 43:37-43.

4. Organización Panamericana de la Salud/Organización Mundial de la Salud. Análisis preliminar de la situación de salud de Venezuela. http:/ /www. ops-oms.org.ve/site/venezuela/ven-sit-saludnuevo.htm (accedido el 05/Jun/2007).

5. García R, Hernández E, Rodríguez-Bonfante C, Jiménez M, Bonfante-Cabarcas R, Añez N, et al. Primer consenso venezolano sobre la enfermedad de Chagas: conclusiones y recomendaciones. Av Cardiol 2001; 21:14-23.

6. Añez N, Crisante G, Rojas A, Díaz N, Añez-Rojas N, Carrasco H, et al. La cara oculta de la enfermedad de Chagas de Venezuela. Bol Dir Malariol Saneam Ambient 2003; 43:45-57.

7. Añez N, Carrasco H, Parada H, Crisante G, Rojas A, Gonzalez N, et al. Acute Chagas' disease in western Venezuela: a clinical, seroparasitologic and epidemiologic study. Am J Trop Med Hyg 1999; 60:215-22.

8. Rodríguez-Bonfante C, Amaro A, García M, Wohlert LEM, Guillen P, García RA, et al. Epidemiología de la enfermedad de Chagas en el municipio Andrés Eloy Blanco, Lara, Venezuela: infestación triatomínica y seroprevalencia en humanos. Cad Saúde Pública 2007; 23:1133-40.

9. Castañera MB, Lauricella MA, Chuit R, Gurtler RE. Evaluation of dogs as sentinels of the transmission of Trypanosoma cruzi in a rural area of northwestern Argentina. Ann Trop Med Parasitol 1998; 92:671-83.

10. Cardinal M, Castañera M, Lauricella M, Cecere M, Ceballos L, Vázquez-Prokopec G, et al. A prospective study of the effects of sustained vector surveillance following community-wide insecticide application on Trypanosoma cruzi infection of dogs and cats in rural northwestern Argentina. Am J Trop Med Hyg 2006; 75:753-61.

11. Feliciangeli D, Torrealba JW. Observaciones sobre Rhodnius prolixus (Hemiptera, Reduviidae) en su biotopo silvestre Copernicia tectorum. Bol Dir Malariol Saneam Ambient 1977; 17:198-205.

12. Gómez-Núnez J. Resting places, dispersal and survival of co-tagged adult Rhodnius prolixus. J Med Entomol 1969; 6:83-6.

13. Lent H, Wygodzinsky P. Revision of Triatominae (Hemiptera, Reduviidae), and their significance as vectors of Chagas' disease. Bull Am Mus Nat Hist 1979; 163:123-520.

14. Reyes-Lugo M, Irauzquin B. Desarrollo y sobrevivencia de huevos y ninfas de Panstrongylus geniculatus Latreille, 1811 (Hemiptera, Reuviidae Triatominae) en un gallinero. Archivos Venezolanos de Medicina Tropical 1997; 1:93-7.
15. Reyes-Lugo M, Rodríguez-Acosta B. Domiciliation of the selvatic Chagas disease vector Panstrongylus geniculatus Latreille, 1811 (Triatominae: Reduviidae) in Venezuela. Trans R Soc Trop Med Hyg 2000; 94:508.

16. Feliciangeli D, Carrasco H, Patterson J, Suarez B, Martínez C, Medina M. Mixed domestic infestation by Rhodnius prolixus Stäl, 1859 and Panstrongylus geniculatus Latreille, 1811, vector incrimination, and seroprevalence for Trypanosoma cruzi among inhabitants in El Guamito, Lara State, Venezuela. Am J Trop Med Hyg 2004; 71:501-5.

17. Tonn R, Otero M, Mora E, Espinola H, Carcavallo R. Aspectos biológicos, ecológicos y distribución geográfica de Triatoma maculata (Erichson 1848), (Hemiptera, Reduviidae), en Venezuela. Bol Dir Malariol Saneam Ambient 1978; 18:16-24.

18. Pifano F. La epidemiología de la enfermedad de Chagas en Venezuela. Arch Venez Med Trop Parasitol Med 1973; 5:171184.

19. Luitgards-Moura J, Borges-Pereira J, Costa J, Zauza P, Rosa-Freitas M. On the possibility of autochthonous Chagas disease in Roraima, Amazon region, Brazil, 2000-2001. Rev Inst Med Trop São Paulo 2005; 47:45-54.

20. Cortés L, Suárez H. Triatominos (Reduviidae: Triatominae) en un foco de enfermedad de Chagas en Talaigua Nuevo (Bolívar, Colombia). Biomédica (Bogotá) 2004; 25:568-74.

21. Ferreira AW, Belem ZR, Lemos EA, Reed SG, Campos-Neto A. Enzyme-linked immunosorbent assay for serological diagnosis of Chagas' disease employing a Trypanosoma cruzi recombinant antigen that consist of four different peptides. J Clin Microbiol 2001; 39:4390-5.

22. Cheng KY, Chang CD, Salbilla VA, Kirchhoff LV, Leiby DA, Schochetman G, Shah DO. Immunoblot assay using recombinant antigens as a supplemental test to confirm the presence of antibodies to Trypanosoma cruzi. Clin Vaccine Immunol 2007; 14:355-61.

23. Chiurillo MA, Crisante G, Rojas A, Peralta A, Dias M, Guevara P, et al. Detection of Trypanosoma cruzi and Trypanosoma rangeli infection by duplex PCR assay based on telomeric sequences. Clin Diagn Lab Immunol 2003; 10:775-9.

24. Aldana E, Lizano E. Índice de defecación y éxito reproductivo de Triatoma maculata (Hemiptera: Reduviidae) en condiciones de laboratorio. Rev Biol Trop 2004; 52:927-30.

25. Luitgards-Moura JF, Vargas AB, Almeida CE, Magno-Esperança G, Agapito-Souza R, Folly-Ramos E, et al. A Triatoma maculata (Hemiptera, Reduviidae, Triatominae) population from Roraima, Amazon Region, Brazil, has some bionomic characteristics of a potential Chagas' disease vector. Rev Inst Med Trop São Paulo 2005; 47:131-7.

26. Cova-García P, Suárez MA. Estudio de los triatominos en Venezuela. Caracas: Tipografía Vargas S.A.; 1959. (Publicaciones de la División de Malariología, 11). 
27. Feliciangeli DM, Hernández M, Suárez B, Martínez C, Bravo A, Bracho J, et al. Comparación de métodos de captura intradoméstica de triatominos vectores de la enfermedad de Chagas en Venezuela. Bol Dir Malariol Saneam Ambient 2007, XLVII:10317.

28. Soto A, Barazarte H, Molina D. Primer registro de Eratyrus mucronatus, Stäl 1959 (Hemíptera, Reduvidae) en el ambiente domiciliario en Venezuela. Entomotrópica 2001; 16:215-7.

29. Reyes L, Silescky E, Cerdas C, Chinchilla M, Guerrero O, Presencia de anticuerpos contra Trypanosoma cruzi en perros de Costa Rica. Parasitol Latinoam 2002; 57:66-8.

30. Zeledón R, Solano G, Burstin L, Swartzwelder JC. Epidemiological pattern of Chagas' disease in an endemic area of Costa Rica. Am J Trop Med Hyg $1975 ; 24: 214-25$.

31. Beard CB, Pye G, Steurer FJ, Rodriguez R, Campman R, Peterson AT, et al. Chagas disease in a domestic transmission cycle, southern Texas, USA. Emerg Infect Dis 2003; 9:103-5.

32. Bradley KK, Bergman DK, Woods JP, Crutcher JM, Kirchhoff LV. Prevalence of American trypanosomiasis (Chagas disease) among dogs in Oklahoma. J Am Vet Med Assoc 2000; 217:1853-7.
33. Crisante G, Rojas A, Teixeira MM, Añez N. Infected dogs as a risk factor in the transmission of human Trypanosoma cruzi infection in western Venezuela. Acta Trop 2006; 98:247-54.

34. Gürtler RE, Cécere MC, Rubel DN, Petersen RM, Schweigmann NJ, Lauricella MA, et al. Chagas disease in north-west Argentina: infected dogs as a risk factor for the domestic transmission of Trypanosoma cruzi. Trans R Soc Trop Med Hyg 1991; 85:741-5.

35. De Andrade AL, Zicker F, De Oliveira RM, Da Silva IG, Silva SA, De Andrade SS, et al. Evaluation of risk factors for house infestation by Triatoma infestans in Brazil. Am J Trop Med Hyg 1995; 53:443-7.

36. Feliciangeli MD, Sanchez-Martin MJ, Suarez B, Marrero R, Torrellas A, Bravo A, et al. Risk factors for Trypanosoma cruzi human infection in Barinas state, Venezuela. Am J Trop Med Hyg 2007; 76:91521.

Recibido el 09/Oct/2007

Versión final presentada el 11/Feb/2008

Aprobado el 28/Feb/2008 